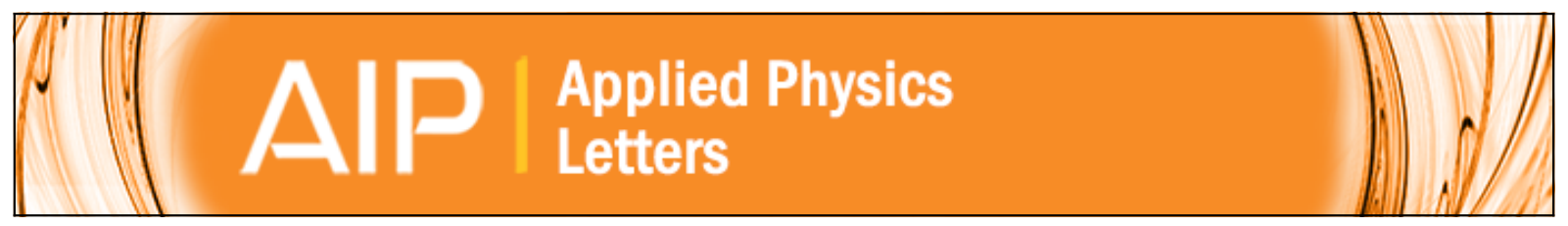

Selective formation of Ohmic junctions and Schottky barriers with electrodeposited ZnO

Shawn Chatman, Bernard J. Ryan, and Kristin M. Poduska

Citation: Applied Physics Letters 92, 012103 (2008); doi: 10.1063/1.2828702

View online: http://dx.doi.org/10.1063/1.2828702

View Table of Contents: http://scitation.aip.org/content/aip/journal/apl/92/1 ?ver=pdfcov

Published by the AIP Publishing

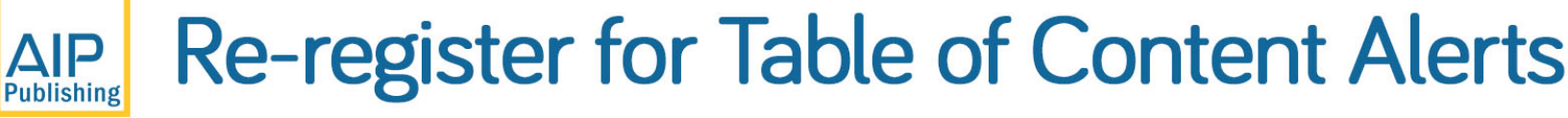

\section{Create a profile.




\title{
Selective formation of Ohmic junctions and Schottky barriers with electrodeposited $\mathrm{ZnO}$
}

\author{
Shawn Chatman, Bernard J. Ryan, and Kristin M. Poduska ${ }^{a), b)}$ \\ Department of Physics and Physical Oceanography, Memorial University of Newfoundland, St. John's, \\ Newfoundland AlB 3X7, Canada
}

(Received 3 October 2007; accepted 5 December 2007; published online 2 January 2008)

\begin{abstract}
Constant-potential electrochemical synthesis of $\mathrm{ZnO}$ on metal substrates enables selective formation of either Ohmic or Schottky-barrier contacts. Using a mildly acidic nitrate-based aqueous electrolyte, there is a substrate-dependent deposition potential below which electrodeposited $\mathrm{ZnO}$ heterojunctions display Schottky response with high contact resistances $\left(\sim 10^{5} \Omega\right)$ and above which Ohmic behavior and low contact resistances $(\sim 1 \Omega)$ occur. Voltammetric evidence for Zn metal deposition, in conjunction with Schottky-barrier heights that are consistent with values expected for a $\mathrm{ZnO}-\mathrm{Zn}$ junction, suggests that more negative deposition potentials create a $\mathrm{Zn}$-based interface between the substrate and $\mathrm{ZnO}$ that leads to rectifying behavior. (C) 2008 American Institute of Physics. [DOI: 10.1063/1.2828702]
\end{abstract}

Zinc oxide $(\mathrm{ZnO})$ is a wide-band, direct-gap semiconductor that is $n$ type in its native form due to unintentional hydrogen doping, regardless of synthesis method. ${ }^{1-4}$ As such, its ability to form rectifying (Schottky) junctions with metals is one characteristic that promotes its use in diodes, varistors, UV detectors, gas sensors, and piezoelectric transducers. ${ }^{5}$ There is also a demonstrated need for low-resistance Ohmic contacts to $\mathrm{ZnO}$ for optical and piezoelectric applications. ${ }^{6}$ While many performance improvements have been realized, it remains a challenge to apply predictive power to determine what conditions will yield optimal Schottky or Ohmic responses in $\mathrm{ZnO} /$ metal heterojunctions. ${ }^{5,7}$ Here, we show that electrochemical deposition methods can be used to selectively form either Ohmic or Schottky contacts between polycrystalline $\mathrm{ZnO}$ and metals-without compromising the optical response of the $\mathrm{ZnO}$ - simply by tuning the applied potential during deposition. We show that this potential selectivity is intimately related to a Zn-based interfacial layer that forms at more negative deposition potentials. Because the resulting barrier heights of these one-step, electrochemically synthesized Schottky junctions are competitive with those prepared by more expensive and resource-intensive methods, our method offers promise for greater economy and control over $\mathrm{ZnO}$ heterojunctions for device applications.

Recent reviews highlight substantial efforts to improve the quality of Schottky contacts between $\mathrm{ZnO}$, single crystalline or polycrystalline, and high purity precious metals with high work functions $(\mathrm{Au}, \mathrm{Pd}, \mathrm{Pt}){ }^{5,7}$ Conversely, lower work function metals and alloys (often based on $\mathrm{Al}$ and $\mathrm{Ag}$ ) have been targeted for Ohmic contacts on $\mathrm{ZnO}^{5-8}$ Many approaches for controlled current-voltage response of surface contacts focus on modification of the $\mathrm{ZnO} /$ metal interface through acid, plasma, laser, or thermal treatments. ${ }^{7,9-11}$ The mechanisms behind such improvements are not always investigated, in part because the surface chemistry of $\mathrm{ZnO}$ is extremely complex due to the existence of polar and nonpolar faces. ${ }^{5}$

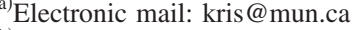

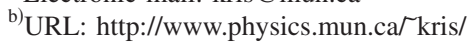

Electrochemical methods have been widely applied to metal deposition, but their use for preparation of functional oxide materials is still a growing area of research. ${ }^{12-14}$ Our thin films were prepared using a method described elsewhere ${ }^{4}$ based on a nitrate-reduction reaction using $0.01 \mathrm{M}$ $\mathrm{Zn}\left(\mathrm{NO}_{3}\right)_{2}$ in ultrapure water $(p \mathrm{H}=5)$. Substrates were polycrystalline $\mathrm{Pt}, \mathrm{Au} / \mathrm{Cr} / \mathrm{glass}$, or stainless steel (316 series) and were cleaned in $\mathrm{HCl}$ and $\mathrm{H}_{2} \mathrm{SO}_{4}$ prior to use. Cyclic voltammetry data for these different substrates in contact with the working electrolyte were collected with a Hokuto Denko HA 501 potentiostat. Constant applied potentials between -0.70 and $-1.50 \mathrm{~V}$ (vs $\mathrm{Ag} / \mathrm{AgCl}$ reference) at $70{ }^{\circ} \mathrm{C}$ yielded $\mathrm{ZnO}$ films with thicknesses $\sim 1 \mu \mathrm{m}$, as determined with contactmode atomic force microscopy (Asylum Research MFP-3D). Structural confirmation was enabled by $\mathrm{x}$-ray diffraction (XRD) data obtained with a Rigaku D/MAX 2200PC ( $\mathrm{Cu} K \alpha$ radiation) and analyzed with the LATCON software package. ${ }^{15}$ Optical absorption edges were calculated from diffuse reflectance data (Ocean Optics SD2000, 45 incident angle, collinear reflectance collector). Current-voltage $(I-V)$ characteristics of deposited samples were assessed with a Keithley 2400 source meter, employing stainless steel compression contacts $\left(0.06 \mathrm{~cm}^{2}\right)$.

Electrochemical $\mathrm{ZnO}$ deposition produces either Ohmic or rectifying contacts, as shown in Fig. 1. The electrical response of these $\mathrm{ZnO}$ heterojunctions is strongly correlated with the potential applied during deposition. For example, $\mathrm{ZnO}$ deposits on stainless steel prepared at $-0.9 \mathrm{~V}$ exhibit Ohmic behavior [Fig. 1(a)] with through-layer resistances of $1-10 \Omega$. However, more negative deposition potentials ( $\leqslant$ $-1.1 \mathrm{~V})$ show much higher perpendicular-to-layer resistances $\left(10^{3}-10^{6} \Omega\right)$ even though the $\mathrm{ZnO}$ films have similar thicknesses. In addition, asymmetric rectifying behavior was observed for deposits prepared at these more negative deposition potentials [Fig. 1(b)], indicative of a Schottky barrier at the $\mathrm{ZnO} /$ substrate junction. This Ohmic-Schottky deposition potential threshold is also evident on $\mathrm{Au}(-0.8 \mathrm{~V}$ vs $\mathrm{Ag} / \mathrm{AgCl})$ and $\mathrm{Pt}(-1.2 \mathrm{~V}$ vs $\mathrm{Ag} / \mathrm{AgCl})$ substrates. In contrast, semiconducting substrates with band gaps similar to that of $\mathrm{ZnO}$, such as polycrystalline indium tin oxide $\left(E_{g}\right.$ 

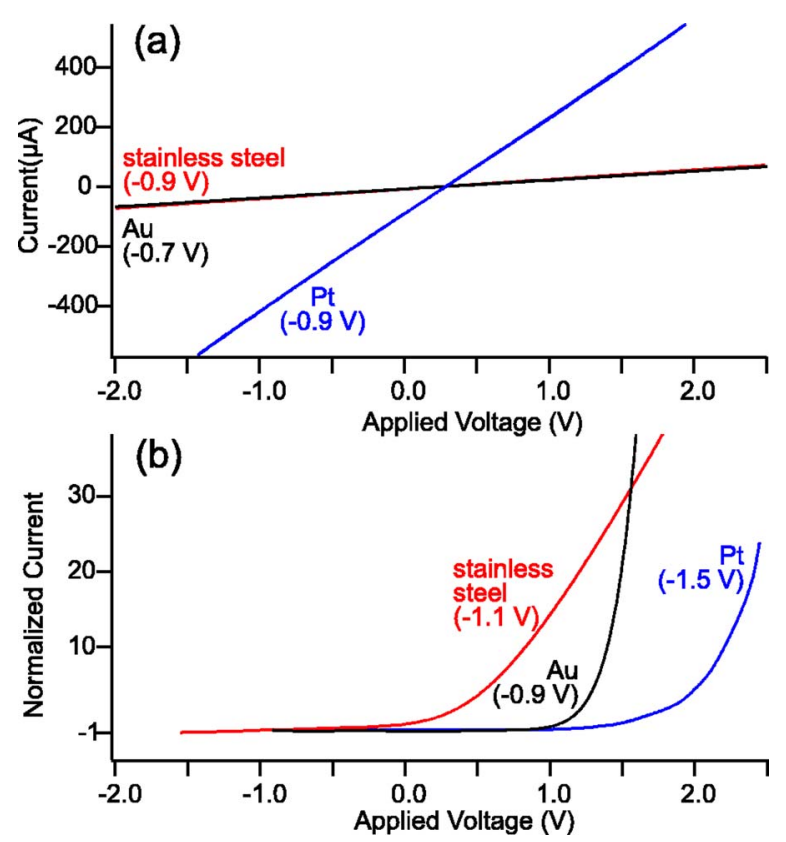

FIG. 1. (Color online) Electrodeposited $\mathrm{ZnO}$ exhibits an Ohmic currentvoltage response when prepared at more positive deposition potentials (a), in contrast with asymmetric Schottky behavior for more negative deposition potentials (b). Current values in (b) are scaled relative to reverse-bias leakage currents $(\sim 10 \mathrm{nA}$ for $\mathrm{Au}$ and $\mathrm{Pt}$ and $\sim 100 \mathrm{nA}$ for stainless steel). Positive voltage indicates forward bias.

$\approx 3.7$ ), always yielded Ohmic contacts with electrodeposited $\mathrm{ZnO}$, regardless of deposition potential.

A broad range of complementary experiments confirms that our results are consistent with interfacial effects, rather than deposition-potential-related changes in the $\mathrm{ZnO}$ film itself. XRD analyses for samples deposited at a potential between -0.9 and $-1.5 \mathrm{~V}$ showed diffraction peaks consistent with those of hexagonal wurtzite $\mathrm{ZnO}$ 's space group $\left(P 6_{3} m c\right)$ and lattice constants $a=3.255 \pm 0.001 \AA$ and $c=5.217 \pm 0.002 \AA$, which are in good agreement with accepted values (3.250 and $5.207 \AA$, JCPDS No. 36-1451). ${ }^{16}$ Relative peak intensity data show that our films are truly polycrystalline but with a preference for (001) orientation, as is typical for electrodeposited $\mathrm{ZnO}{ }^{4,14,20}$ Optical absorption edge values for these same $\mathrm{ZnO}$ films, calculated from diffuse reflectance measurements, lie in the accepted range for native $\mathrm{ZnO}(3.3 \pm 0.1 \mathrm{eV}){ }^{9,11}$

The rectifying behavior of our electrodeposited junctions compare favorably with $\mathrm{ZnO}$-based Schottky junctions prepared by other methods, with forward-current to leakagecurrent ratios of $\sim 50: 1$ and no breakdown at reverse-bias voltages up to $2 \mathrm{~V}$. It is customary to compare the rectifying behavior with an ideal Schottky response as outlined below:

$$
J=A^{*} T^{2} \exp \left(\frac{-q \Phi_{B}}{k T}\right) \exp \left(\frac{q(V-I R)}{n k T}\right),
$$

where $J$ is current density, $A^{*}$ is Richardson's constant $\left(A^{*}=32 \mathrm{~A} / \mathrm{cm}^{2} \mathrm{~K}^{2}\right), T$ is temperature, $q$ is the fundamental unit of charge, $\Phi_{B}$ is the Schottky-barrier height, $k$ is Boltzmann's constant, $V$ is the applied voltage, $I$ is the resulting current, $R$ is the series resistance, and $n$ is the ideality factor. Schottky-barrier heights for our electrodeposited junctions, calculated by fitting $I-V$ data [Fig. 1(b)] to Eq. (1) showed slight variations with substrate: $0.73 \pm 0.05 \mathrm{eV}$ for steel, $0.85 \pm 0.05 \mathrm{eV}$ for $\mathrm{Au}$, and $0.90 \pm 0.05 \mathrm{eV}$ for Pt. All values

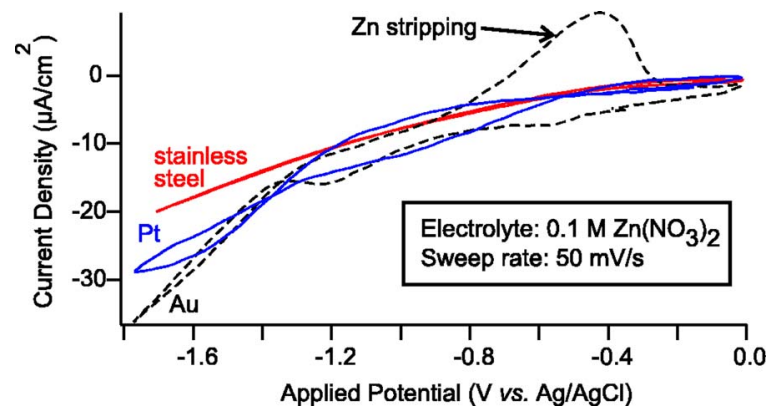

FIG. 2. (Color online) Cyclic voltammograms for Au (dashed curve) in $0.1 \mathrm{M} \mathrm{Zn}\left(\mathrm{NO}_{3}\right)_{2}$ show an anodic peak near $-0.5 \mathrm{~V}$ that is characteristic of $\mathrm{Zn}$ metal stripping. The suppression of stripping peaks on stainless steel and Pt substrates (solid curves) during cyclic voltammetry studies in the same electrolyte is consistent with the formation of an electrochemically irreversible $\mathrm{Zn}$ alloy, as described in Ref. 21.

fall comfortably within the range of $\mathrm{ZnO}$ Schottky-barrier heights reported by others $(0.6-1.0 \mathrm{eV}) .{ }^{7-11,17,18}$ Another measure of the rectifying quality is the ideality factor $(n)$, with a value of 1 corresponding to a perfect exponential transition from leakage-current to forward-current flow. High values of the ideality factor $(>2)$ are attributed to the existence of multiple current pathways. ${ }^{7}$ Our electrodeposited $\mathrm{ZnO}$ junctions have high ideality factors $(n \sim 10$, determined over $0.5 \mathrm{~V}$ ), commensurate with $\mathrm{ZnO}$ Schottky diodes formed using chemical-vapor deposition, ${ }^{19}$ while more ideal Schottky junctions have been prepared by other methods $(n$ $=1.0-2.0$, determined over $\sim 0.1 \mathrm{~V})$. $^{7,9,10,17}$

To a first approximation, the best Schottky barriers occur when the metal's work function $\left(\Phi_{m}\right)$ is very different from the electron affinity $\left(\chi_{\mathrm{sc}}\right)$ of the semiconductor,

$$
\Phi_{B}=\Phi_{m}-\chi_{\mathrm{sc}} .
$$

For electrodeposited junctions, evidence suggests that a composition-related change in the interfacial electronic states also affects Schottky-barrier formation, height, and ideality. Applied deposition potentials more negative than $-1.5 \mathrm{~V}$ generally favor $\mathrm{Zn}$ metal formation over $\mathrm{ZnO}{ }^{20}$ At more positive deposition potentials, electrochemical $\mathrm{ZnO}$ formation can be preceded by a $\mathrm{Zn}$ metal prelayer, as reported by others. ${ }^{14}$ Figure 2 shows that reversible deposition and stripping of $\mathrm{Zn}$ metal is possible using our electrolyte. In contrast, $\mathrm{ZnO}$ formation is not reversible and has no current associated with it due to the fact that $\mathrm{Zn}$ does not change its oxidation state. ${ }^{20}$ Substrates such as Pt can support an electrochemically produced $\mathrm{Zn}$ surface alloy, although the details of its composition and structure remain elusive. ${ }^{21}$

To confirm that the earliest stages of deposition are critical for controlling the Ohmic/rectifying responses of our $\mathrm{ZnO}$ electrodeposits, we compared constant-potential deposition to a pulsed deposition sequence. Rectifying responses were observed for pulse-prepared junctions $(-1.5 \mathrm{~V}$ for $10 \mathrm{~s}$ to deposit $\mathrm{Zn}$ metal, followed by subsequent deposition at $-0.9 \mathrm{~V}$ to deposit $\mathrm{ZnO}$ ), whereas a constant deposition potential of $-0.9 \mathrm{~V}$ yielded Ohmic contacts. We also note that, despite the large difference in work functions of our substrates $\left(\Phi_{\mathrm{Au}}=5.1 \mathrm{eV}, \Phi_{\mathrm{Pt}}=5.7 \mathrm{eV}\right),{ }^{22}$ barrier heights of the electrodeposited junctions on these different substrates show a much smaller spread $(0.8 \pm 0.1 \mathrm{eV})$. Furthermore, using Eq. (2) to estimate an effective substrate work function, we find a value of $4.5 \pm 0.1 \mathrm{eV}$ which is on par with the work func- 
tion reported for $\mathrm{Zn}(4.4 \mathrm{eV}){ }^{22}$ Thus, the rectifying response in electrodeposited $\mathrm{ZnO}$ heterojunctions is consistent with contacts at a $\mathrm{Zn}$ metal interface.

We established a more definite link between Schottky behavior and the presence of a $\mathrm{Zn}$-based prelayer at the buried interface using scanning electron microscopy (SEM) (FEI Quanta 400) with energy dispersive x-ray (EDX) analysis. $\mathrm{ZnO} /$ substrate interfaces were exposed by mechanically detaching films from their substrates by cooling epoxycoated films in liquid nitrogen. EDX data show higher $\mathrm{Zn}$ content at the $\mathrm{ZnO} /$ substrate interface relative to the $\mathrm{ZnO}$ film's air interface. EDX investigations on the stainless steel substrates after $\mathrm{ZnO}$ film removal show no evidence of $\mathrm{Zn}$ content, suggesting that the $\mathrm{Zn}$-based prelayer contributing to the Schottky response is strongly adhered to the $\mathrm{ZnO}$ film. Contrast variations in the backscattered electron images from the $\mathrm{ZnO} /$ substrate interface suggest that the $\mathrm{Zn}$-based prelayer may have thickness inhomogeneities, which would be consistent with multiple conduction pathways ${ }^{7}$ implied by our films' high ideality factors.

In summary, potentiostatic electrochemical deposition of $\mathrm{ZnO}$ on metal substrates provides selectivity between Ohmic contacts and Schottky junctions, with no need for annealing. This selectivity can be attributed to potential-dependent formation of a $\mathrm{Zn}$-based interface between the substrate and $\mathrm{ZnO}$ electrodeposit, thereby yielding barrier heights consistent with $\mathrm{ZnO}-\mathrm{Zn}$ contacts. The electrodeposited junctions compare well with $\mathrm{ZnO}$ Schottky diodes synthesized using more resource-intensive synthesis methods, offering an opportunity for greater economy and control over $\mathrm{ZnO}$ heterojunctions for device applications.

We thank Dr. R. Mason, H. Gillespie, and M. Shaffer (XRD and SEM facilities at Memorial University of Newfoundland), as well as the NSERC (Canada) and the Canada Foundation for Innovation for funding.
${ }^{1}$ S. F. J. Cox, E. A. Davis, S. P. Cottrell, P. J. C. King, J. S. Lord, J. M. Gil, H. V. Alberto, R. C. Vilao, J. Piroto Duarte, N. Ayres de Campos, A. Weidinger, R. L. Lichti, and S. J. C. Irvine, Phys. Rev. Lett. 86, 2601 (2001).

${ }^{2}$ C. G. Van de Walle and J. Neugebauer, Nature (London) 423, 626 (2003).

${ }^{3}$ N. H. Nickel and K. Fleischer, Phys. Rev. Lett. 90, 197402 (2003).

${ }^{4}$ T. Ren, H. R. Baker, and K. M. Poduska, Thin Solid Films 515, 7976 (2007).

${ }^{5}$ Ü. Özgür, Ya. I. Alivov, C. Liu, A. Teke, M. A. Reshchikov, S. Dogan, V. Avrutin, S.-J. Cho, and H. Morkoç, J. Appl. Phys. 98, 041301 (2005).

${ }^{6}$ H.-K. Kim, S.-H. Han, and T.-Y. Seong, Appl. Phys. Lett. 77, 1647 (2000).

${ }^{7}$ J. Wright, R. Khanna, L. Voss, L. Stafford, B. Gila, D. Norton, S. Pearton, H.-T. Wang, S. Jang, T. Anderson, J. J. Chen, B. S. Kang, F. Ren, H. Shen, J. R. LaRoche, and K. Ip, Appl. Surf. Sci. 253, 3766 (2007).

${ }^{8}$ S. Liang, H. Sheng, Y. Liu, Z. Huo, Y. Lu, and H. Shen, J. Cryst. Growth 225, 110 (2001)

${ }^{9}$ K. Ip, B. P. Gila, A. H. Onstine, E. S. Lambers, Y. W. Heo, K. H. Baik, S. Kim, J. R. LaRoche, and F. Ren, Appl. Phys. Lett. 84, 5133 (2004).

${ }^{10}$ S.-H. Kim, H.-K. Kim, and T.-Y. Seong, Appl. Phys. Lett. 86, 022101 (2005).

${ }^{11}$ M.-S. Oh, D.-K. Hwang, J.-H. Lim, Y.-S. Choi, and S.-J. Parka, Appl. Phys. Lett. 91, 042109 (2007).

${ }^{12}$ S. Chatman, A. J. G. Noel, and K. M. Poduska, J. Appl. Phys. 98, 113902 (2005).

${ }^{13}$ I. M. Dharmadasa and J. Haigh, J. Electrochem. Soc. 153, G47 (2006).

${ }^{14}$ B. Canava and D. Lincot, J. Appl. Electrochem. 30, 711 (2000).

${ }^{15} \mathrm{D}$. Schwarzenbach, LATCON: Program for the LS-Refinement of Lattice Constants (Uni Lausanne, Lausanne, Switzerland, 1975).

${ }^{16}$ Joint Commission on Powder Diffraction Standards-International Centre for Diffraction Data, Powder Diffraction File (2003) (URL www.icdd.com).

${ }^{17}$ R. C. Neville and C. A. Mead, J. Appl. Phys. 41, 3795 (1970).

${ }^{18}$ L. J. Brillson, H. L. Mosebacker, M. J. Hetzer, Y. Strzhemechny, D. C. Look, G. Cantwell, J. Zhang, and J. J. Song, Appl. Phys. Lett. 90, 102116 (2007).

${ }^{19}$ M. C. Newton, S. Firth, and P. A. Warburton, Appl. Phys. Lett. 89, 072104 (2006).

${ }^{20}$ S. Peulon and D. Lincot, J. Electrochem. Soc. 145, 864 (1998).

${ }^{21}$ A. Sode, W. Li, Y. Yang, P. C. Wong, E. Gyenge, K. A. R. Mitchell, and D. Bizzotto, J. Phys. Chem. B 110, 8715 (2006).

${ }^{22} \mathrm{D}$. Neamen, An Introduction to Semiconductor Devices (McGraw-Hill, Boston, 2006). 